\title{
APPLICATION OF $2^{3}$ FULL-FACTORIAL DESIGN FOR DEVELOPMENT AND OPTIMIZATION OF BIOCOMPATIBLE, BIODEGRADABLE SOLID LIPID NANOPARTICLES CONTAINING CURCUMIN
}

\author{
Hamdy M. Dawaba ${ }^{1,2} *$, Ahmed M. Samy ${ }^{1}$, Mohamed I. Fetouh ${ }^{1}$, \\ Fathy I. Abd-Allah ${ }^{1}$ and Nutan M. T. ${ }^{2}$ \\ 1. Department of Pharmaceutics and Industrial Pharmacy, College of Pharmacy, Al-Azhar \\ University - Cairo, Egypt. \\ 2. Department of Pharmaceutical Sciences, Texas A\&M Health Science Center, Kingsville \\ -Texas, USA.
}

\begin{abstract}
Curcumin (C), a natural anticancer agent suffers extremely low aqueous solubility and rapid systemic elimination, therefore, the aim from the present study was to develop and optimize biocompatible, biodegradable solid lipid nanoparticles containing curcumin (CSLNs) using Solvent Injection Method. The components selected to develop the SLNs were Glycerol MonoStearate (GMS; the lipidic carrier), Poloxamer 407 (P407; Surfactant) and Ethanol (solvent for the drug and the lipidic carrier). The combination and ratios for the optimization process were carried out using $2^{3}$ full-factorial designs. The experimental design runs ( 8 formulations $\mathrm{H} 1-\mathrm{H} 8$ ) were prepared and the design dependent responses (assessment of particle size, Entrapment Efficiency \% and the in vitro release study) were characterized. The developed formulae showed a nanometric particle size range (203.0 $345.0 \mathrm{~nm})$, high Entrapment Efficiency \% (62.77-87.42\%) and prolonged release over $24 \mathrm{hr}$ periods (55.97-89.64\%). These results were analyzed using JMP ${ }^{\circledR} 10$ software and its analytical tools were used to draw Pareto charts and the interactions plots. On the basis of the software analysis, formulation $\mathrm{H} 9$ with a desirability factor of 0.582 was selected as the optimized formulation and was evaluated for the dependent responses. Formulation H9 showed a particle size of $249.1 \mathrm{~nm}, 74.51 \%$ Entrapment efficiency, $85.72 \%$ in vitro release over $24 \mathrm{hr}$ and these results suggested that the solid lipid nanoparticles formulations could be a promising method to sustain the release of curcumin.
\end{abstract}

\section{INTRODUCTION}

Traditional medicine is known to be fertile ground for the source of modern medicines (Corson and Crews, 2007; Aggarwal and Sung, 2008; Wu et al., 2011) as Nature's chemical diversity and complexity form a unique source of molecules for a wide range of therapeutic targets (Balunas and Kinghorn, 2005; Coimbra et al., 2011).

Several natural compounds at present are being appreciated because of their broad spectrum of activities making them more appropriate to interfere in multifactorial diseases, such as cancer (Nobili et al., 2009; Pan et al., 2009; Harvey et al., 2010).

In addition, compared to synthetic compounds, natural bioactive compounds generally have better safety profiles, are well accepted by the public (opinion) and are usually relatively cheap (Pan et al., 2009; Gupta et al., 2010). However, their physicochemical properties are generally not drug-like and pose a number of challenges that need to be overcome for their establishment as effective therapeutics (Shoji and Nakashima, 2004; Nobili et al., 2009; Gupta et al., 2010; Coimbra et al., 2011). 
A great example of these natural compounds is curcumin which has considerable potentials against various human diseases like cancer (Anand $\boldsymbol{e t}$ al., 2007; Tsai et al., 2011; Yallapu et al., 2012). Though curcumin has demonstrated safety and efficacy profiles (as a chemotherapeutic agent) but it has restrictive pharmaceutical role because of its extremely low aqueous solubility and rapid systemic elimination which severely curtails its bioavailability profile (Anand $e t$ al., 2008; Anand et al., 2010; Mohanty and Sahoo, 2010).

Therefore, design and development of biodegradable controlled drug delivery system for curcumin was the main research aspect on which extensive work has been done in the past few decades (Mulik et al., 2009).

Solid Lipid Nanoparticles (SLNs) were developed as the first generation of Lipid based Nanoparticless and are being extensively studied as promising approaches for poorly soluble drugs (Almeida and Souto, 2007; Martins et al., 2007; Nayak et al., 2010).

SLNs as drug delivery systems have a well known advantages such as good tolerability, lower cytotoxicity, higher bioavailability by oral administration, increase in the drug stability as well as other advantages provided by lipid excipients, such as biodegradability and cost effectiveness that promote their use as novel drug carriers (Mehnert and Mader, 2001; Mukherjee et al., 2007). Also since they are consisting of physiological and biodegradable lipids, lipid nanoparticles are suitable for the incorporation of lipophilic, hydrophilic, and poorly water-soluble drugs within the lipid matrix in considerable amounts (Bunjes $\boldsymbol{e t}$ al., 2001).

Lipidic carriers used to prepare SLNs can be highly purified lipids such as tristearin or tripalmitin, hard fats such as stearic acid or behenic acid, waxes such as cetyl palmitate, and acylglycerol mixtures such as compritol or GMS (Souto and Müller, 2006).

The objectives behind the selection of GMS (a non-polar lipid, $\mathrm{C}_{21} \mathrm{H}_{42} \mathrm{O}_{4}$ ) as the lipid phase to formulate SLNs formulations were its high drug entrapment efficiency as the presence of high amounts of Mono-, Di-glycerides in GMS help the drug to solubilize in the lipid fraction as well as the less defined mixture of acylglycerol provides additional space for drug molecules to get entrapped (Manjunath et al., 2005; Shah and Pathak, 2010).

In addition to that GMS depicts some surface tension activity due to the fact that it is composed of $\sim 50 \%$ of Monoglycerides which was held responsible for the small particle size of GMS-based lipid nanoparticles in comparsion to other lipidic carriers such as Trimyristin and Tristerin which are triglycerides of higher molecular weight and lacking the surface tension activity (Jenning et al., 2000; Nayak $\boldsymbol{e t}$ al., 2010).

Poloxamers or Pluronic (marketed by BASF Corporation) are the series of commercially available difunctional triblock copolymers of non-ionic nature. They comprise of a central block of relatively hydrophobic polypropylene oxide surrounded on both sides by the blocks of relatively hydrophilic poly ethylene oxide and they are regarded as PEO-PPO-PEO copolymers (Kabanov et al., 2002). Among number of natural and synthetic polymers, Poloxamer 407 (P407), a US Food and Drug Administration-approved polymer, is the most attractive due to its biocompatibility, biodegradability as well as its low toxicity profile (Hussain and Saxena, 2012). Also P407 had been used to produce micellar formulations of different drugs to increase their solubility, their metabolic stability and their circulation time (Oh et al., 2004; Zhang et al., 2011; Hussain and Sexana, 2012).

Furthermore, P407 had been used either alone or with other polymers like Carbopol 934 and HPMC to provide controlled release delivery systems of different drugs (Kabanov et al., 2002).

The objective of the present study was to develop SLNs of curcumin and to optimize it for the independent variables selected (amount of glycerol monostearate, concentration of 
poloxamer, and volume of ethyl alcohol) in order to achieve desired particle size with maximum entrapment efficiency (EE \%) and percent cumulative drug release (CDR \%). Factorial design enables all the factors to be varied simultaneously, allowing quantification of the effects caused by independent variables and interactions between them. Many researchers have optimized nanoparticulate formulations using $2^{3}$ full-factorial design (Bozkir and Saka, 2005; Bhavsar et al., 2006; Derakhshandeh et al., 2007; Shah and Pathak, 2010).

\section{MATERIALS AND METHODS}

\section{Materials}

Curcumin $(C ; 98 \%$ pure powder and molecular weight $=368.38 \mathrm{D})$ was purchased from Acros Organics, NJ, USA; Poloxamer 407 (P407) powder from Spectrum Chemicals MFG. CORP., CA, USA; Purified Glycerol MonoStearate (GMS) from VWR, West Chester, PA, USA; Phosphate Bufferd Saline (PBS) pH 7.4 powder packets from SigmaAldrich Co, St. Louis, MO, USA. Absolute Ethyl alcohol (Ethanol) from Avantor Performance Materials INC., NJ, USA. Methanol HPLC Grade from EMD chemicals In., NJ, USA. All other chemicals were standard pharmaceutical grade and used without further purification.

\section{Methods}

\section{Experimental Design of SLNs}

In this study, a $2^{3}$ full-factorial experimental design was used to optimize SLNs. In order to optimize, the amount of GMS (X1), concentration \% of P407 (X2) and volume of Ethanol (X3) were selected as the independent variables while the particle size in $\mathrm{nm}(\mathrm{Y} 1)$, Entrapment Efficiency percent (EE \%, Y2) and Cumulative Drug Released percent (CDR $\%$, Y3) were selected as the responses parameters. Eight formulations of SLNs (H1-H8) were prepared according to the experimental design where the actual values of the independent variables as well as the observed values for the responses parameters are illustrated in Table I.

Table (1): $2^{3}$ full factorial design of C-SLNs formulations:

\begin{tabular}{|c|c|c|c|c|c|c|}
\hline \multirow{2}{*}{$\begin{array}{c}\text { Formula } \\
\text { Code }\end{array}$} & \multicolumn{2}{|c|}{ Independent Parameters } & \multicolumn{3}{|c|}{ Dependent Parameters } \\
\cline { 2 - 7 } & $\begin{array}{c}\text { GMS } \\
(\mathbf{m g})\end{array}$ & $\begin{array}{c}\text { P407 } \\
\text { concentration } \\
(\boldsymbol{\%})\end{array}$ & $\begin{array}{c}\text { Ethanol } \\
\text { Volume } \\
(\mathbf{m l})\end{array}$ & $\begin{array}{c}\text { Particle Size } \\
(\mathbf{n m} \pm \text { SD) }\end{array}$ & $\begin{array}{c}\text { EE\% } \\
\mathbf{\pm} \text { SD }\end{array}$ & $\begin{array}{c}\text { CDR \% } \\
\text { over 24 } \\
\text { hr }\end{array}$ \\
\hline H1 & -1 & -1 & -1 & $294.9 \pm 2.8$ & $79.22 \pm 0.89$ & 87.64 \\
\hline H2 & -1 & -1 & +1 & $262.9 \pm 0.7$ & $71.21 \pm 0.74$ & 88.3 \\
\hline H3 & -1 & +1 & -1 & $214.1 \pm 1.6$ & $66.78 \pm 0.89$ & 89.64 \\
\hline H4 & -1 & +1 & +1 & $203.0 \pm 4$ & $62.77 \pm 0.83$ & 55.97 \\
\hline H5 & +1 & -1 & -1 & $345.0 \pm 4.7$ & $87.42 \pm 0.96$ & 56.5 \\
\hline H6 & +1 & -1 & +1 & $320.2 \pm 3.4$ & $82.53 \pm 0.88$ & 74.55 \\
\hline H7 & +1 & +1 & -1 & $268.2 \pm 3.3$ & $76.58 \pm 0.81$ & 77.5 \\
\hline H8 & +1 & +1 & +1 & $249.3 \pm 0.7$ & $68.1 \pm 0.93$ & 69.34 \\
\hline
\end{tabular}


Actual and coded values of the independent parameters:

\begin{tabular}{|c|c|c|c|c|}
\hline Independent Parameter & Low Level & Actual Value & High Level & Actual Value \\
\hline GMS amount (mg) X1 & -1 & 100 & +1 & 200 \\
\hline P407 concentration \% X2 & -1 & 1 & +1 & 2 \\
\hline Ethanol Volume (ml) X3 & -1 & 1 & +1 & 2 \\
\hline
\end{tabular}

\section{Preparation of Solid Lipid Nanoparticles containing Curcumin (CSLNs)}

Solid lipid nanoparticles containing curcumin (CSLNs) were prepared according to solvent injection technique reported early by (Schubert and Muller-Goymann, 2003; Shah and Pathak, 2010) with slight modification where curcumin (2\% of the lipid phase) and specified amount of GMS was dissolved in the specified volume of ethanol with gentle heating. The resulting solution was rapidly injected into the $10 \mathrm{ml}$ of aqueous phase containing specified amount of P407 that was continuously stirred at $400 \mathrm{rpm}$ for $30 \mathrm{~min}$ on a magnetic stirrer; $0.1 \mathrm{NHCl}(4 \mathrm{ml})$ was added to the dispersion and the dispersion then was centrifuged to $10,000 \mathrm{rpm}$ for $30 \mathrm{~min}$ at $10^{\circ} \mathrm{C}$ in Allegra ${ }^{\circledR}$ 64R Benchtop centrifuge (Beckman Coulter Inc, Palo Alto, CA, USA), and aggregates were resuspended using $10 \mathrm{ml}$ distilled water containing 4\% poloxamer 407 (by weight) as stabilizer with stirring at 1,000 rpm for $10 \mathrm{~min}$ and lyophilized in FreeZone ${ }^{\circledR} 2.5$ tabletop Freeze dryer (Labconco Corporation, Kansas city, Missouri, USA).

\section{HPLC analysis method}

Curcumin analysis was preformed according to Cui et al. (2009) with gentle

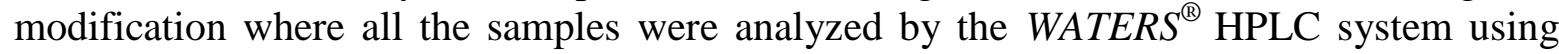
Perkin Elmer HPLC column (SPHERI-5 RP - 18, Perkin Elmer LLC, Norwalk city, CT, USA) with the following specifications $5 \mu \mathrm{m}, 4.6 \mathrm{~mm} \times 250 \mathrm{~mm}$ Preceded by a guard column (SecurityGurad $^{\mathrm{TM}}$, Phenomenex Inc., Torrance, CA, USA) filled with C18 cartridges $(4 \mathrm{x}$ $2.00 \mathrm{~mm}$ ID) at room temperature. The mobile phase was Methanol: $\mathrm{H}_{2} \mathrm{O}$ (containing $3.6 \%$ glacial acetic acid) $(73: 27, \mathrm{v} / \mathrm{v})$, freshly prepared on the day of use, filtered through a 0.45 $\mu \mathrm{m}$ filter and was degassed by sonication for $15 \mathrm{~min}$ (Dandekar and Patravale, 2009). The flow rate $1 \mathrm{ml} / \mathrm{min}$, the retention time for curcumin was $6.3 \mathrm{~min}$ and curcumin was detected at $428 \mathrm{~nm}$ with a sample run time of $10 \mathrm{~min}$.

\section{Physical Characterization of C-SLNs formulations Determination of particle size}

The particle size of C-SLNs formulations was determined by Photon correlation spectroscopy (PCS) employing the ZetaPALs ${ }^{\circledR}$ particle size analyzer (Brookhaven Instruments Incorporation, New York, USA) that was fitted with a $4 \mathrm{~mW} \mathrm{He-Ne}$ diode laser operating at $633 \mathrm{~nm}$. An aliquot of lyophilized SLNs formulations was resuspended in deionized water (DIW) prior to measurements to yield a suitable scattering intensity. Analysis was performed at a fixed angle of $90^{\circ}$ to the incident light and data were collected over a period of $9 \mathrm{~min}$. The particle size analysis data were evaluated using the hydrodynamic diameter (Nayak et al., 2010).

\section{Determination of Encapsulation Efficiency Percent (EE \%)}

The Encapsulation Efficiency Percent (EE \%) of the developed C-SLNs formulations was determined as described earlier by (Tiyaboonchai $\boldsymbol{e t}$ al., 2007; Nayak $\boldsymbol{e t}$ al., 2010) with a suitable modification. Ten milligrams of lyophilized C-SLNs formulae were accurately weighed and dispersed in $10 \mathrm{ml}$ of methanol. The samples were then 
centrifuged at $13,000 \mathrm{rpm} / 30 \mathrm{~min}$. The amount of curcumin in the supernatant was determined using HPLC analysis method and the EE \% was determined as follows:

$\mathrm{EE} \%=\left[\left(\mathrm{T}_{\mathrm{CU}}-\mathrm{S}_{\mathrm{CU}}\right) / \mathrm{T}_{\mathrm{CU}}\right] \times 100$

Where $\mathrm{T}_{\mathrm{CU}}$ stands for the total amount of curcumin added to the formulation and $\mathrm{S}_{\mathrm{CU}}$ stands for the amount of drug measured in the supernatant.

\section{In-Vitro Release Profile of curcumin}

The cumulative curcumin percent released (CDR \%) was determined as described earlier by (Nayak et al., 2010; Bisht $\boldsymbol{e t}$ al., 2007) with a suitable modification where known amount of lyophilized C-SLNs formulations (100 mg) were dispersed in PBS pH 7.4 and the dispersion was divided into 8 aliquots $(1 \mathrm{ml}$ each) in microfuge tubes which were kept in a thermo stable water bath at $37^{\circ} \mathrm{C} \pm 0.5^{\circ} \mathrm{C}$. At predetermined time intervals, the dispersion was centrifuged at $200 \times g$ for $5 \mathrm{~min}$ and the resulted pellets were then redissolved in $1 \mathrm{ml}$ of methanol. After that, the drug content was determined using HPLC analysis method and the concentration of the released curcumin was calculated using a standard curve of curcumin in methanol.

\section{RESULTS AND DISCUSSION}

\section{Preparation of Curcumin Solid Lipid Nanoparticles (C-SLNs) formulations}

C-SLNs formulations were successfully prepared by Solvent Injection Method which gave a yellowish sponge product after the freeze-drying process. The lyophilized formulations were easily redispersed in water and the resultant suspensions were subjected to physical characterization tests.

\section{Physical Characterization of C-SLNs formulations}

Evaluation of the physical characteristics of the developed C-SLNs formulations is a crucial step in determining the efficiency of the delivery system as it influences the physical stability, cellular uptake, biodistribution and release of the encapsulated drug (Acharya $\boldsymbol{e t}$ al., 2009; Mohanty and Sahoo, 2010).

\section{Determination of particle size}

Particle size is a critical determinant for the fate of administered nanoparticles as it governs the distribution of nanoparticles in the body and the small size of particles is considered advantageous for passive targeting to tumor tissue by enhanced permeability and retention effect (Panyam et al., 2002; Sahu et al., 2008; Das et al., 2009; Mohanty and Sahoo, 2010; Akhtar et al., 2012). It is clear that the particle size measurements obtained for all the eight formulations were in the submicron range $(203.00-345.00 \mathrm{~nm})$ where formulation H4 showed the smallest value $(203.0 \mathrm{~nm})$ and $\mathrm{H} 5$ showed the highest value $(345.00 \mathrm{~nm})$. The best explanation for the small particle size range obtained using GMS as the lipid phase comes from the surface tension activity provided by the high percent of Monoglycerides (main composition in GMS) which facilitate emulsification process and improve the surfactant film around the nanoparticles leading to prevention of particle aggregation and crystal growth (Westesen et al., 1993; Ahlin et al., 1998; Jenning et al., 2000; Nayak et al., 2010).

\section{Determination of Encapsulation Efficiency (EE)}

Determination of the EE \% for the developed SLNs formulations is an important factor for determining the therapeutic efficacy of drug delivery system (Mohanty and Sahoo, 2010). The encapsulation efficiency (EE \%) of curcumin was determined by 
measuring the concentration of free drug in the dispersion medium (methanol) after centrifugation of SLN suspension using HPLC analysis method. From table (1) the EE \% values showed a range between $62.77 \%$ and $87.42 \%$ with the highest EE \% obtained was in case of $\mathrm{H} 5$ and the lowest $\mathrm{EE} \%$ in case of $\mathrm{H} 4$ indicating relatively good entrapment efficiency of curcumin in the developed SLNs formulations, probably because of its lipophilic character. It is known that three drug incorporation models can be deduced to describe how drug molecules are incorporated in the SLNs formulations:

(1) Solid Solution Model.

(2) Core-Shell Model, Drug Enriched Shell.

(3) Core-Shell Model, Drug-Enriched Core (Müller et al., 2000; Lv et al., 2009).

The drug incorporation model relates to specific nature of the solid lipid matrix as well as the lipophilicity of drug (Schäfer-Korting et al., 2007; Lv et al., 2009). Depending on the previous reports and literatures we believe that C-SLNs formulations were comprised of a high melting point GMS core with a protective hydrophilic coating of P407 (GarcíaFuentes et al., 2002; Heiati et al., 1996). From the obtained results in table (1) it was evident that the EE \% increased with increasing GMS content as the increase in GMS content can afford more space to encapsulate drug under the condition of given surfactant concentration in outer phase (Lv et al., 2009). Also, another factor should be considered for the relatively high EE \% of curcumin in GMS-based SLNs formulations which is the effect of Poloxamer 407 (P407). Based on the reported studies by Fang et al. (2008); Hsu et al. (2003); Liu et al. (2007a); Singh et al. (2008) and Lv et al. (2009), the SLNs formulations developed using P407 in the outer phase had the highest EE\% over other known surfactants such as Brij 78, Tween 80 and Tween 20. These results might be related to various effects such as the hydrophile-lipophile balance (HLB) value, structure of the surfactant and its concentration in the outer phase for example high concentration of Poloxamer in the outer phase results in increasing the thickness of the hydrophilic coating and then more drugs can disperse and dissolve in it (Lv et al., 2009).

\section{In-Vitro Release Profile}

The release profile of curcumin from the developed SLNs was investigated over a period of 24 hours and the final release results after $24 \mathrm{hr}$ are shown in table (1) while the complete release over the whole period is represented in figure (1). In order to mimic the in vivo condition, PBS pH 7.4 was chosen as the release medium and since the solubility of curcumin in aqueous solutions is extremely low, it will remain in the form of crystals in the releasing medium (Bisht et al., 2007; Nayak et $\boldsymbol{a l . , 2 0 1 0}$ ). At the predetermined time intervals, the dispersion was centrifuged $(200 \times \mathrm{g} / 5 \mathrm{~min})$ in order to separate the released curcumin crystals and it did not affect the lipid nanoparticles because they do not sediment at this speed (Bisht et al., 2007; Nayak $\boldsymbol{e t}$ al., 2010). The curcumin amount present in the precipitated pellets was then determined using HPLC analysis system after being dissolved in methanol and the concentration of the released curcumin was calculated using the standard curve of curcumin in methanol. From table (1) it was clear that the in-vitro release of curcumin from the investigated formulations was markedly different from one formulation to another and the highest release \% was $89.64(\mathrm{H} 4)$ while the lowest \% was 55.97 (H5) which could be explained based on the particle size measurements obtained as the increase in particle size causes a decrease in the total surface area and as a result, the CDR \% after $24 \mathrm{hr}$. 


\section{Statistical analysis of experimental data}

The results of the experimental design were analyzed using JMP ${ }^{\circledR} 10$ software that was very helpful in elucidating the relationship between the dependent and independent variables through providing the main effects, interactions profile, response surface and contour plots. Additionally it was used to express the mathematical relationships between the independent variables and the dependent responses in the form of the polynomial equations listed in table (2). The confidence that the regression equations would predict the observed values better than the mean for $\mathrm{Y}_{1}, \mathrm{Y}_{2}$ and $\mathrm{Y}_{3}$ was $99.83 \%, 98.58 \%$ and $97.96 \%$, respectively. These polynomial equations represented the quantitative effect of process variables $\left(\mathrm{X}_{1}, \mathrm{X}_{2}\right.$ and $\left.\mathrm{X}_{3}\right)$ and their interaction on the designated responses and they were used to generate the response surface plots which represented the simultaneous effect of any two variables on the response parameter taking one variable at constant level. The values of the coefficient $X_{1}, X_{2}$ and $X_{3}$ are related to the effect of these variables on the designated response. Coefficients with more than one factor term represent interaction terms and coefficient positive sign represents a synergistic effect, while a negative sign indicates an antagonistic effect.

Table (2): Regression equations for the responses:

\begin{tabular}{|c|c|}
\hline Response & Regression equation \\
\hline Particle size $(\mathrm{nm}) \mathrm{Y}_{1}$ & $354.075+0.5765 \mathrm{X} 1-86.95 \mathrm{X} 2-41.35 \mathrm{X} 3-$ \\
& $0.035 \mathrm{X} 1 \mathrm{X} 2-0.003 \mathrm{X} 1 \mathrm{X} 3+13.4 \mathrm{X} 2 \mathrm{X} 3$ \\
\hline \multirow{2}{*}{ Entrapment Efficiency $(\mathrm{EE} \%) \mathrm{Y}_{2}$} & $82.1637+0.129675 \mathrm{X} 1-8.5525 \mathrm{X} 2-5.6425 \mathrm{X} 3-$ \\
& $0.02195 \mathrm{X} 1 \mathrm{X} 2-0.00675 \mathrm{X} 1 \mathrm{X} 3+0.205 \mathrm{X} 23$ \\
\hline Cumulative Drug Released (CDR \%) & $45.7025-0.14225 \mathrm{X} 1+15.705 \mathrm{X} 2+35.915 \mathrm{X} 3+$ \\
$\mathrm{Y}_{3}$ & $0.0931 \mathrm{X} 1 \mathrm{X} 2-0.1156 \mathrm{X} 1 \mathrm{X} 3-9.69 \mathrm{X} 2 \mathrm{X} 3$ \\
\hline
\end{tabular}

Effect of $X_{1}, X_{2}$ and $X_{3}$ on $Y_{1}, Y_{2}$ and $Y_{3}$

The selected independent variables (the amount of GMS, concentration of P407 and volume of ethanol) significantly influenced the dependant parameters (particle size, EE \% and CDR \%) that is very much evident from the results in Table I. Figure (2) represent the pareto chart while figures ( 3 and 4 ) represent the main effects plot and the interaction effects plot of GMS amount in $\mathrm{mg}\left(\mathrm{X}_{1}\right), \mathrm{P} 407$ concentration \% $\left(\mathrm{X}_{2}\right)$ and ethanol volume in $\mathrm{ml}\left(\mathrm{X}_{3}\right)$ on the dependable responses for the developed C-SLNs formulations. From these figures it was obvious that $X_{1}$ and $X_{2}$ had the main effects on the dependant parameters while $X_{3}$ had the same effect as $X_{2}$ but to a lesser extent. $X_{1}$ had a positive effect on both $Y 1$ and $Y 2$ while it had a negative effect on $\mathrm{Y} 3$ while $\mathrm{X} 2$ and $\mathrm{X} 3$ had negative effects on $\mathrm{Y} 1$ and $\mathrm{Y} 2$ and positive effects on Y3. Table (3) show the ANOVA analysis for the dependable parameters where the statistical significance of each effect was tested by comparing the mean square against an estimate of the experimental error.

From the previous results, the following conclusions could be drawn:

1. Increased amount of GMS caused an increase in both the particle size and the EE \% and a decrease in the CDR \% for the developed C-SLNs formulations and this effect regarding the particle size could be interpreted to the fact that the size of lipid nanoparticles is highly dependent on lipid concentration as lipid tend to coalesce at high lipid concentration and according to Stoke's law, this behavior can be explained by difference in density between internal and external phase (Leroux et al., 1994). Additionally, Schubert and MüllerGoymann, (2003) have reported that an increase in particle size of SLNs is due to reduction in the diffusion rate of the solute molecules in the outer phase as a result of viscosity increase in the lipid-solvent phase. 
Table (3): Analysis of variance for the dependent responses:

\begin{tabular}{|c|c|c|c|c|c|c|c|c|c|}
\hline & \multicolumn{2}{|l|}{ Particle Size (nm, Y1) } & \multicolumn{3}{l|}{ CD \% (Y2) } \\
\hline Source & $\begin{array}{c}\text { Sum of } \\
\text { Squares }\end{array}$ & $\begin{array}{c}\text { Mean } \\
\text { Square }\end{array}$ & P-Value & $\begin{array}{c}\text { Sum of } \\
\text { Squares }\end{array}$ & $\begin{array}{c}\text { Mean } \\
\text { Square }\end{array}$ & P-Value & $\begin{array}{c}\text { Sum of } \\
\text { Squares }\end{array}$ & $\begin{array}{c}\text { Mean } \\
\text { Square }\end{array}$ & P-Value \\
\hline X1 & 5397.61 & 5397.61 & 5397.61 & 150.078 & 150.078 & 0.1373 & 619.52 & 619.52 & 0.1297 \\
\hline X2 & 10396.8 & 10396.8 & 10396.8 & 266.228 & 266.228 & 0.1038 & 458.136 & 458.136 & 0.1501 \\
\hline X3 & 941.78 & 941.78 & 941.78 & 80.5815 & 80.5815 & 0.1849 & 32.6432 & 32.6432 & 0.4664 \\
\hline X1X2 & 6.125 & 6.125 & 6.125 & 2.40901 & 2.40901 & 0.6662 & 43.3381 & 43.3381 & 0.4221 \\
\hline X1X3 & 0.045 & 0.045 & 0.045 & 0.227812 & 0.227812 & 0.8879 & 66.8168 & 66.8168 & 0.3574 \\
\hline X2X3 & 89.78 & 89.78 & 89.78 & 0.0210125 & 0.0210125 & 0.9656 & 46.948 & 46.948 & 0.4098 \\
\hline Total error & 28.125 & 28.125 & 28.125 & 7.20101 & 7.20101 & & 26.4265 & 26.4265 & \\
\hline Total (corr.) & 16860.3 & 16860.3 & 16860.3 & 506.746 & & & 1293.83 & & \\
\hline$R^{2}$ & 99.8332 & & & 98.579 & & & 97.9575 & & \\
\hline $\begin{array}{c}R^{2} \text { (adjusted } \\
\text { for d.f.) }\end{array}$ & 98.8323 & & & 90.0528 & & & & \\
\hline $\begin{array}{c}\text { Standard } \\
\text { Error of Est. }\end{array}$ & 5.3033 & & & 2.68347 & & & & & \\
\hline $\begin{array}{c}\text { Mean } \\
\text { absolute error }\end{array}$ & 1.875 & & & 0.94875 & & & & \\
\hline
\end{tabular}


Concerning the EE \%, the behavior of GMS could be explained by the fact that on increasing the amount of GMS, EE \% is bound to increase because of the increased concentration of mono-, di-, and triglycerides that act as solubilizing agents for highly lipophilic drug (Mukherjee et al., 2007). Moreover, the behavior of GMS concerning the CDR \% could be related to its effect on the particle size where the increase in particle size might be due to the increased amount of lipid provides additional space for drug molecules to entrap, thus decreasing the total surface area and as a result, the CDR \% after $24 \mathrm{hr}$ was least for the formulation $\mathrm{H} 5$ that had the maximum particle size of $345.0 \mathrm{~nm}$.

2. The behavior of P407 on the developed C-SLNs formulation is opposite to GMS behavior where it was found that on increasing the concentration \% of P407, both the particle size and $\mathrm{EE} \%$ were decreased but the CDR \% was found to be increased. Concerning the particle size, this behavior is attributed to the reduction in the surface tension between the aqueous phase and the organic phase caused by the increase of the surfactant concentration, also the surfactant helps to stabilize the newly generated surfaces and prevents particle aggregation (Schubert and Müller-Goymann, 2003).

Concerning the EE \%, this behavior may be attributed to the well-known fact that the aqueous solubility of drug increases with increasing concentration of surfactant in aqueous phase (Shah and Pathak, 2010). Concerning the CDR \%, this behavior is attributed to the fact that the corresponding decrease in the particle size causes in turn an increase in the surface area available for dissolution (Shah and Pathak, 2010).

3. The behavior of Ethanol on the developed C-SLNs formulation was similar to that of concentration \% of P407 but to a lesser extent as could be observed in Figures (2, 3 and 4).

Concerning the particle size, the behavior of ethanol could be attributed to the resultant decrease in the viscosity of organic phase that in turn led to increase in the diffusion rate. The behavior of ethanol concerning the $\mathrm{EE} \%$ is related to the fact that curcumin has higher solubility in ethanol as compared to water. The behavior of GMS concerning the CDR \% could be attributable to the corresponding decrease in particle size, which in turn increased the surface area and hence dissolution.

4. The possible interactions between $\mathrm{X} 1 \mathrm{X} 2, \mathrm{X} 2 \mathrm{X} 3$, and $\mathrm{X} 1 \mathrm{X} 3$ for each response were also investigated in figures (2, 3 and 4) Graphically, the interactions are visualized by lack of parallelism in the lines, but in this case, parallel lines obtained for each interaction term(s) for each response parameter(s) indicated lack of interactions, which in turn indicated that the experimental design has maximum efficiency in estimating main effects (Bolton and Bon, 2004).

\section{Optimization of the formulation ingredients}

According to our criteria of lower particle size, higher EE \% and higher CDR \% after $24 \mathrm{hr}$, H9 was developed as the optimized formulation (desirability value of 0.582 ) using $148 \mathrm{mg}$ of GMS, \% of P407 and $\mathrm{ml}$ of ethanol and evaluated for responses. The predicted and experimental values for the responses were recorded in table (4) while the complete release profile was represented in figure 5. From figures (1 and 5) all the investigated C-SLNs formulations as well as $\mathrm{H} 9$ showed a biphasic drug release pattern (i.e. a burst release at the initial state followed by a sustained release state).The first stage of the release (the burst release) was usually attributed to the dissociation of the fraction of drug which is adsorbed onto or nearby the surface of nanoparticles or the polymeric matrix (Shaikh et al., 2009; Misra et al., 2009; Mohanty and Sahoo, 2010; Nayak et al., 2010). Upon placing the nanoparticles within the release medium, the curcumin located onto the SLNs surface was released following a burst profile due to the short diffusion distance for 
the drug adhered on the surface region of the nanoparticles to go in the dissolution medium (Souto et al., 2004). The second stage of release (sustained release), the release profile will slow down and become sustained due to the time required for the entrapped drug to diffuse from the lipid core into the release medium (Nayak et al., 2010) or might be due to the partition of drug in the hydrophobic core of GMS and subsequently diffusion/erosion of polymeric matrix made the drug released from C-SLNs formulations to the aqueous medium (Mohanty and Sahoo, 2010). Our results came in agreement with the studies conducted by Bisht et al. (2007); Tiyaboonchai et al. (2007); Mulik et al. (2009); Shaikh et al. (2009); Mohanty and Sahoo, (2010); Mulik et al. (2010; Nayak et al. (2010) and Wang et al. (2012) who observed the similar trends of in vitro release (i.e. showing an initial burst release followed by a slower and constant release thereafter).

Table (4): Evaluation of the optimized C-SLN formula (H9):

\begin{tabular}{|c|c|c|}
\hline Dependant Response (Y) & Predicted Value & Experimental Value \\
\hline Particle size (nm,Y1) & 240.54 & $249.1 \pm 2.9$ \\
\hline EE \% (Y2) & 71.59 & $74.51 \pm 0.75$ \\
\hline CDR \% (Y3) & 82.97 & 85.72 \\
\hline
\end{tabular}

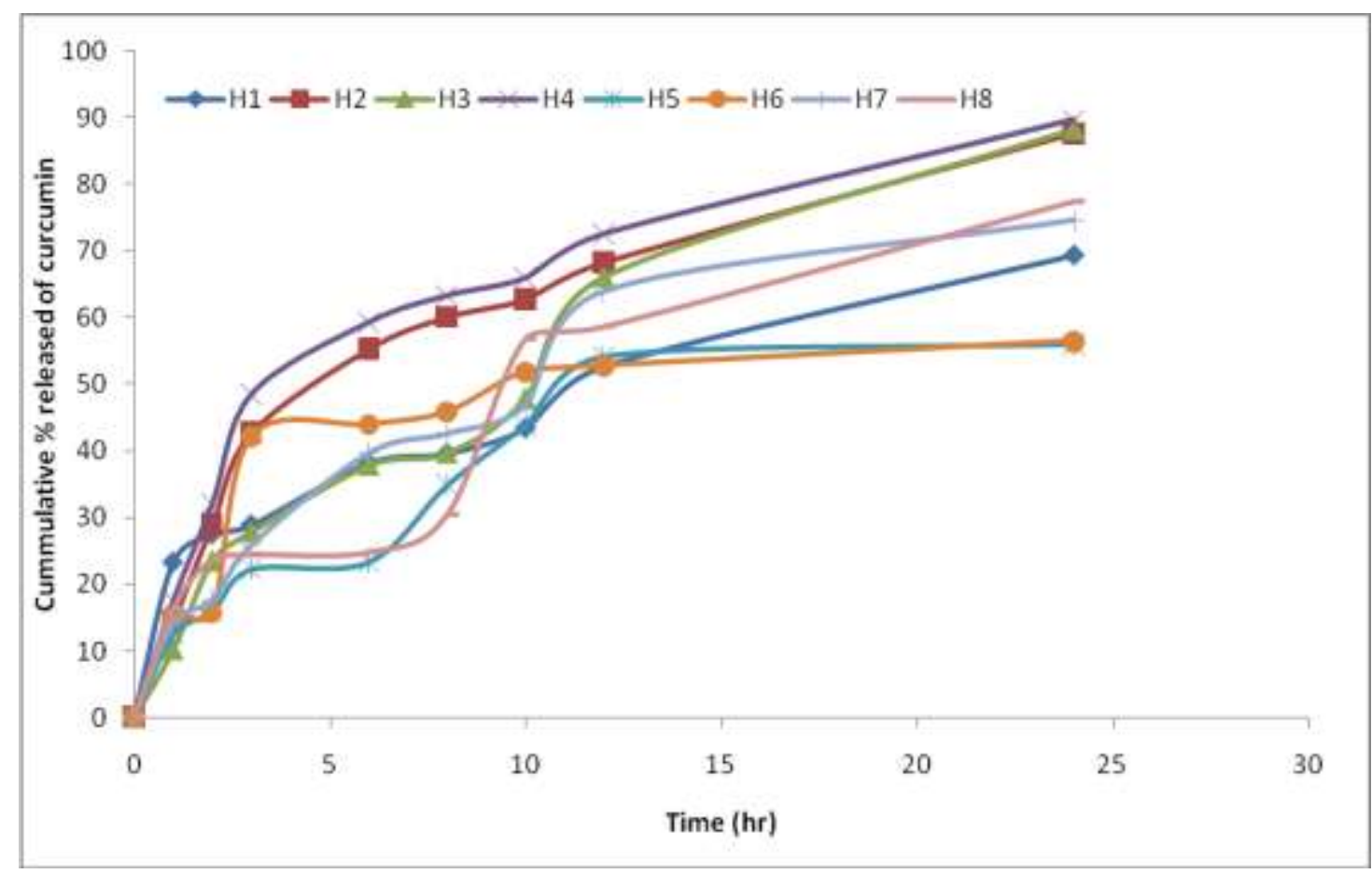

Fig (1): Cumulative \% released of curcumin over $24 \mathrm{hr}$ from the experimental design Formulations (H1-H8). 
A)

Term

P407 Conc ( $9 \%) \times 2(1,2)$

GMS amount(mg)X1(100,200)

Ethanol volume $(\mathrm{ml}) \times 3(1,2)$

P407 Conc $(0 \%) \times 2^{*}$ Ethanol volume ( $\left.\mathrm{ml}\right) \times 3$

GMS amount (mg) X1*P407 Conc ( $g \%) \times 2$

GMS amount ( $\mathrm{mg}) \times 1^{*}$ Ethanol volume (ml) $X 3$
Estimate

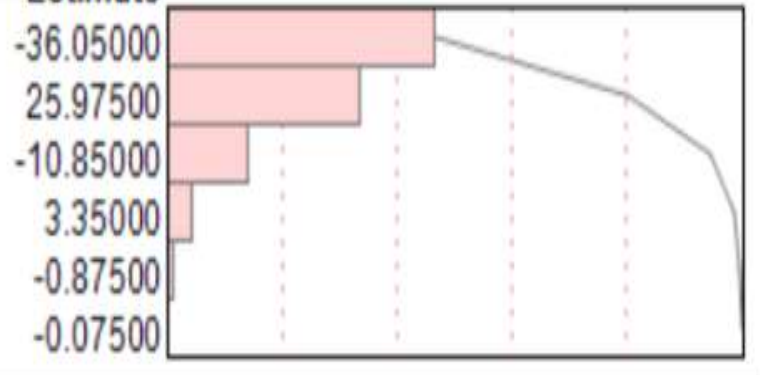

B)

Term

P407 Conc $(9 \%) \times 2(1,2)$

GMS amount(mg) $X 1(100,200)$

Ethanol volume $(\mathrm{ml}) \times 3(1,2)$

GMS amount(mg) $X 1{ }^{*} \mathrm{P} 407 \mathrm{Conc}(\mathrm{g} \%) \times 2$

GMS amount (mg) $X 1^{*} E$ thanol volume $(\mathrm{ml}) \times 3$

P407 Conc $(9 \%) \times 2 *$ Ethanol volume $(\mathrm{ml}) \times 3$
Estimate

$-5.768750$

4.331250

$-3.173750$

$-0.548750$

$-0.168750$

0.051250

C)

Term

GMS amount (mg)X1(100,200)

P407 Conc $(9 \%) \times 2(1,2)$

GMS amount(mg) $X 1^{*} E$ thanol volume $(\mathrm{ml}) X_{3}$

P407 Conc $(9 \%) \times 22^{2}$ Ethanol volume (ml) $X 3$

GMS amount(mg) X1*P407 Conc ( $0 \%) \times 2$

Ethanol volume(m) $X 3(1,2)$
Estimate

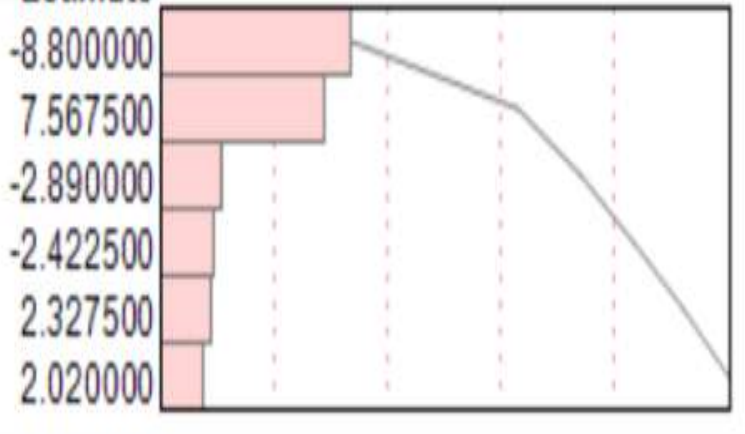

Fig (2): Patero charts showing the effects of $\mathrm{X} 1, \mathrm{X} 2$ and $\mathrm{X} 3$ on $\mathrm{A}$ ) particle size, B) EE \% and C) $\mathrm{CDR} \%$. 
A)

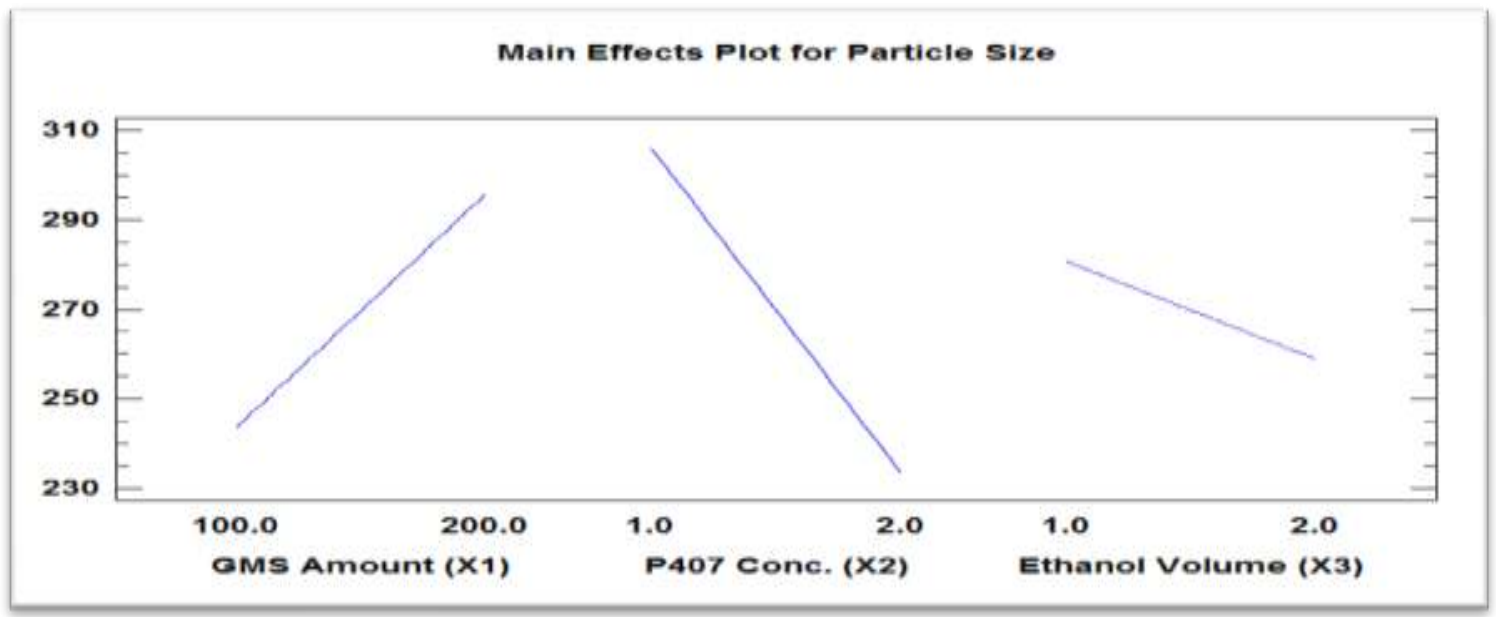

B)

Main Effects Plot for Encapsulation Efriciency

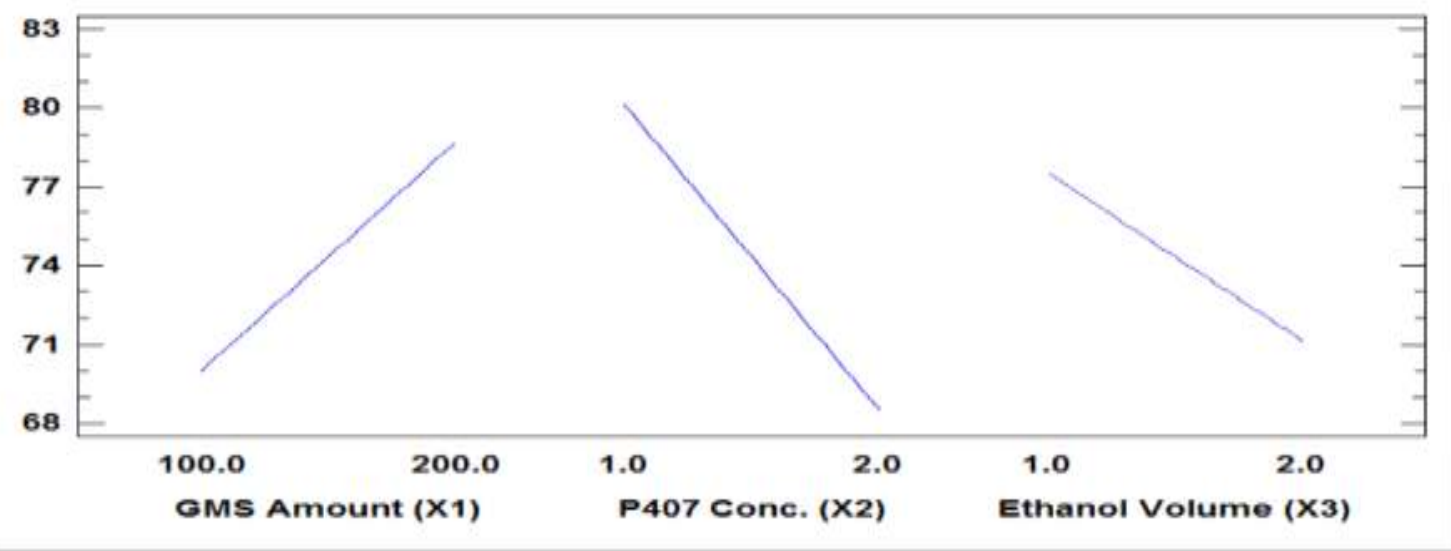

C)

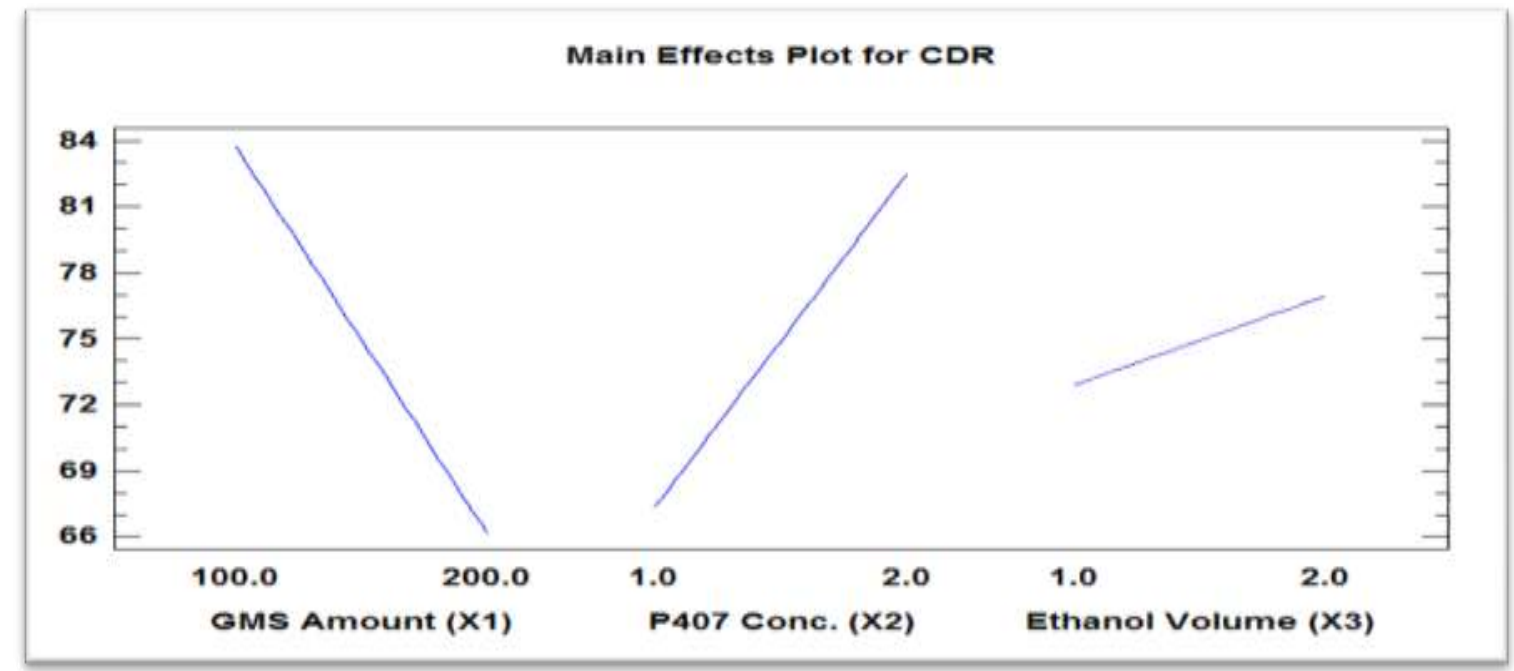

Fig (3): Main effects plot of X1, X2 and X3 on A) particle size, B) EE \% and C) CDR \%. 
A)

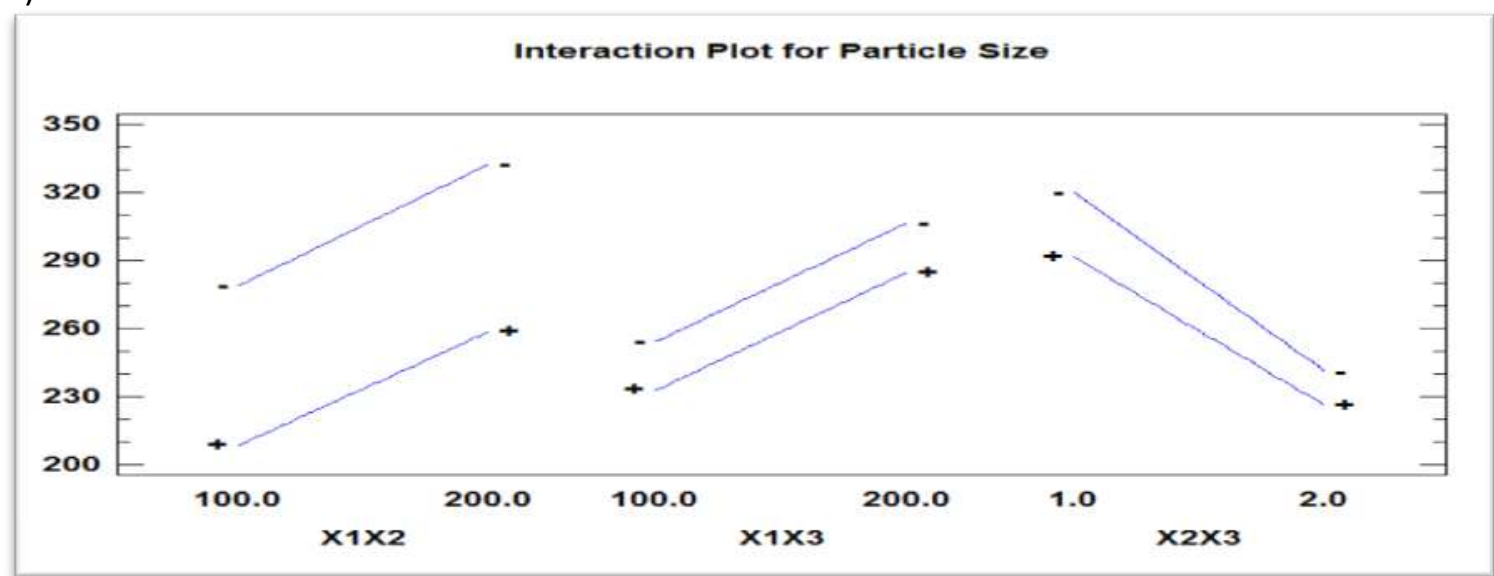

B)

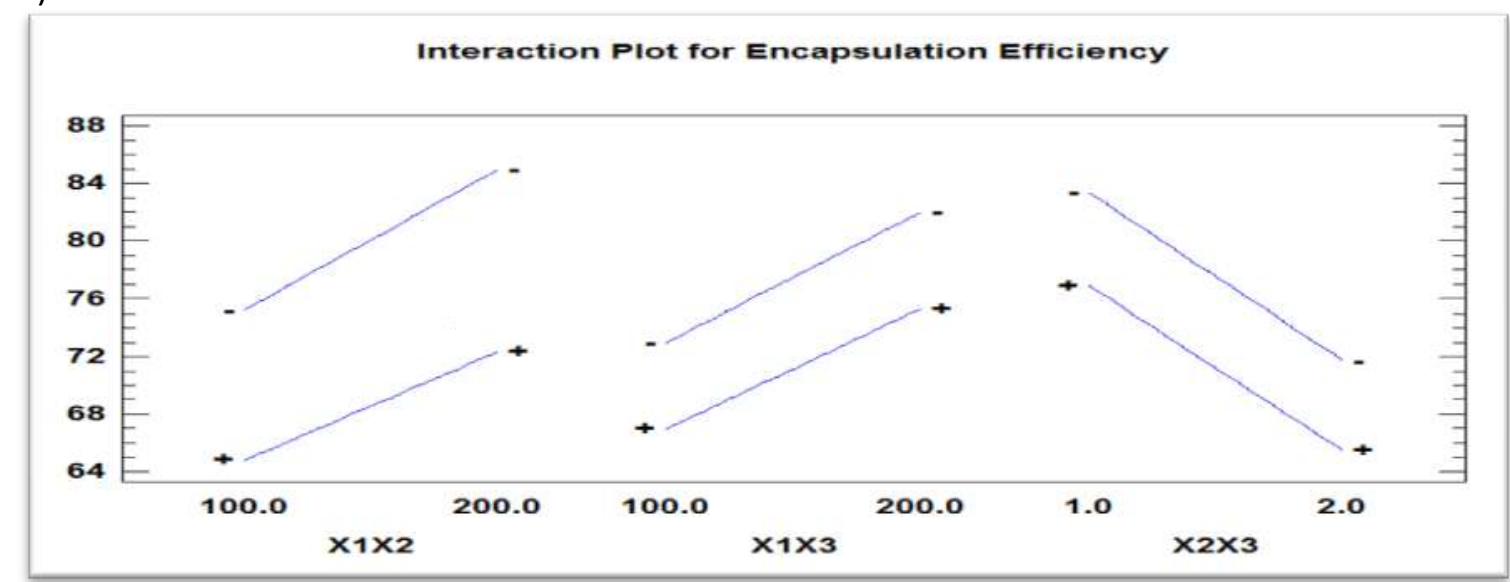

C)

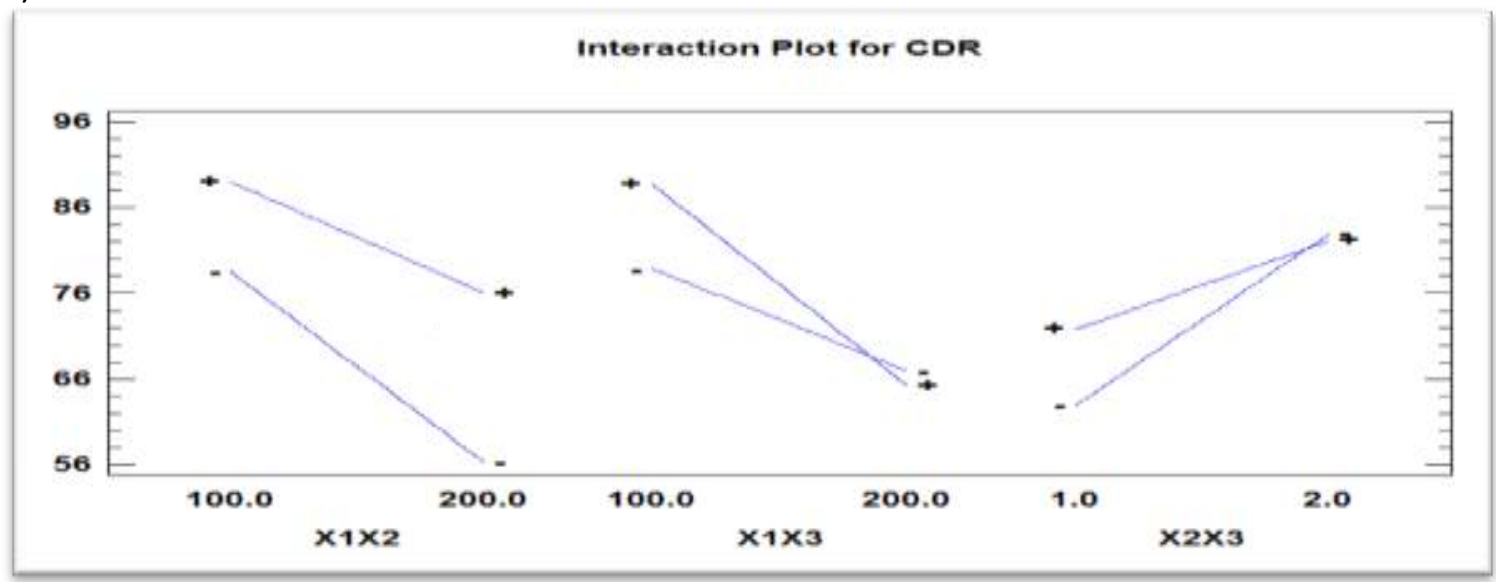

Fig (4): interaction plot of $\mathrm{X} 1, \mathrm{X} 2$ and $\mathrm{X} 3$ on $\mathrm{A}$ ) particle size, B) EE $\%$ and C) CDR \%. 


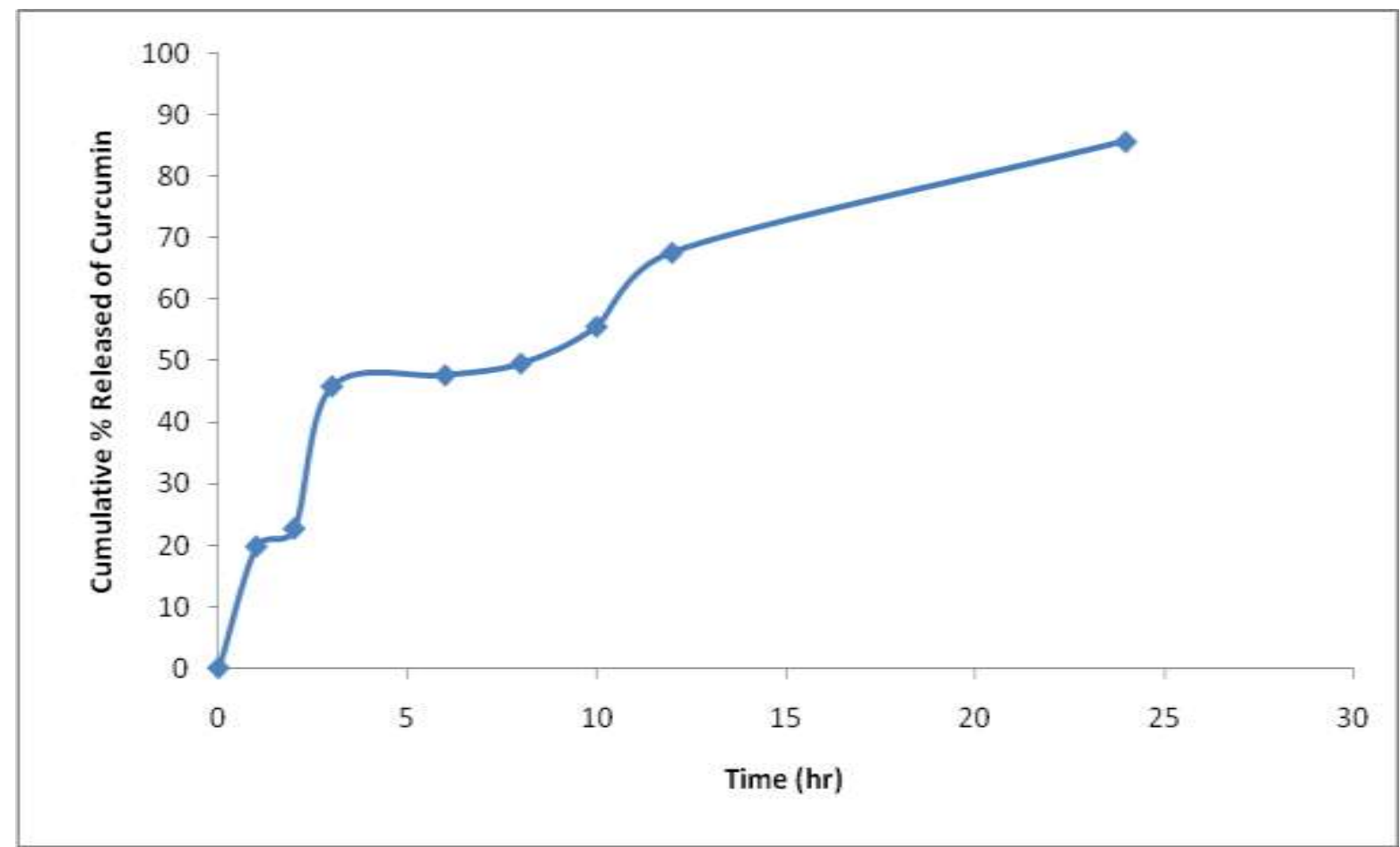

Fig (5): Cumulative \% released of curcumin over $24 \mathrm{hr}$ from Formula H9.

\section{CONCLUSION}

Solid Lipid Nanoparticles of curcumin were successfully developed to yield an optimized formulation with least nanometeric particle size and highest possible entrapment efficiency that could sustain the release of curcumin over $24 \mathrm{hr}$. The use of $2^{3}$ full-factorial design enabled to develop an acceptable formulation using minimum raw materials and in minimum time.

\section{REFERENCES}

Acharya S., Dilnawaz F. and Sahoo S. K.; (2009): Targeted epidermal growth factor receptor nanoparticle bioconjugates for breast cancer therapy, Biomaterials; 30(29):5737-50.

Aggarwal B. B. and Sung B.; (2008): Pharmacological basis for the role of curcumin in chronic diseases: an age-old spice with modern targets, Trends Pharmacol Sci; 30: 85-94.

Ahlin P., Kristl J. and Korbors J. S.; (1998): Optimization of procedure parameters and physical stability of solid lipid nanoparticles in dispersions, Acta pharm; 48:259.

Akhtar F., Rizvi M. A. and Kar S. K.; (2012): Oral delivery of curcumin bound to chitosan nanoparticles cured Plasmodium yoelii infected mice, Biotech Adv; 30:310-20.

Almeida A. J. and Souto E.; (2007): Solid lipid nanoparticles as a drug delivery system for peptides and proteins, Adv Drug Deliv Rev; 59:478-90.

Anand P., Kunnumakkara A. B., Newman R. A. and Aggarwal B. B.; (2007): Bioavailability of Curcumin: Problems and Promises, Mol Pharmaceutics; 4(6):807-18. 
Anand P., Sundaram C., Jhurani S., Kunnumakkara A. B. and Aggarwal B. B.; (2008): Curcumin and cancer: an "old-age" disease with an "age-old" solution, Cancer Lett; 267(1):133-64.

AnandP., Nair H. B., Sung B., Kunnumakkara A. B., Yadav V. R. and Tekmal R. R. et al.; (2010): Design of curcumin-loaded PLGA nanoparticles formulation with enhanced cellular uptake, and increased bioactivity in vitro and superior bioavailability in vivo, Biochem Pharmacol; 79(3):330-8.

Balunas M. J. and Kinghorn A. D.; (2005): Drug discovery from medicinal plants, Life Sci.; 78:431-41.

Bhavsar M. D., Tiwari S. B. and Amiji M. M.; (2006): Formulation optimization for the nanoparticles-in-microsphere hybrid oral delivery system using factorial design, J Control Rel; 110:422-30.

Bisht S., Feldmann G., Soni S., Ravi R., Karikar C. and Maitra A.; (2007): Polymeric nanoparticle encapsulated curcumin ("nanocurcumin"): a novel strategy for human cancer therapy, J Nanobiotechnol; 5:3.

Bolton S. and Bon C.; (2004): Pharmaceutical statistics: practical and clinical applications. 4th ed. New York: Marcel Dekker.

Bozkir A. and Saka O. M.; (2005): Formulation and investigation of 5-FU nanoparticles with factorial design-based studies, IL Farmaco; 60:840-6.

Bunjes H., Drechsler M., Koch M. H. J. and Westesen K.; (2001): Incorporation of the model drug ubidecarenone into solid lipid nanoparticles, Pharm Res.; 18:28793.

Coimbra M., Isacchi B., van-Bloois L., Torano J. S., Ket A., Wu X., Broere F., Metselaar J. M., Rijcken C. J. F., Storm G., Bilia R. and Schiffelers R. M.; (2011): Improving solubility and chemical stability of natural compounds for medicinal use by incorporation into liposomes, Int J Pharm; 416:433-42.

Corson T. W. and Crews C. M.; (2007): Molecular understanding and modern application of traditional medicines: triumphs and trials, Cell; 130:769-74.

Cui J., Yu B., Zhao Y., Zhu W., Li H., Lou H. X. and Zhai G.; (2009): Enhancement of oral absorption of curcumin by self-microemulsifying drug delivery systems, Int J Pharm; 371:148-55.

Dandekar P. P. and Patravale V. B.; (2009): Development and Validation of a StabilityIndicating LC Method for Curcumin, Chromatographia; 69(9/10):871-7.

Das M., Mohanty C. and Sahoo S. K.; (2009): Ligand-based targeted therapy for cancer tissue, Expert Opin Drug Deliv; 6(3):285-304.

Derakhshandeh K., Erfan M. and Dadashzadeh S.; (2007): Encapsulation of 9nitrocamptothecin, a novel anticancer drug, in biodegradable nanoparticles: factorial design, characterization and release kinetics, Eur J Pharm Biopharm; $66: 34-41$.

Fang J. Y., Fang C. L., Liu C. H. and Su Y. H.; (2008): Lipid nanoparticles as vehicles for topical psoralen delivery: solid lipid nanoparticles (SLN) versus nanostructured lipid carriers (NLC), Eur J Pharm Biopharm; 70:633-40.

García-Fuentes M., Torres D. and Alonso M. J.; (2002): Design of lipid nanoparticles for the oral delivery of hydrophilic macromolecules, Colloid Surf B; 27:159-68. 
Gupta S. C., Kim J. H., Prasad S. and Aggarwal B. B.; (2010): Regulation of survival, proliferation, invasion, angiogenesis, and metastasis of tumor cells through modulation of inflammatory pathways by nutraceuticals, Cancer Metastasis Rev.; 29:405-34.

Harvey A. L., Clark R. L., Mackay S. P. and Johnston B. F.; (2010): Current strategies for drug discovery through natural products, Expert Opin Drug Discov; 5:559-68.

Heiati H., Phillips N. C. and Tawashi R.; (1996): Evidence for phospholipid bilayer formation in solid lipid nanoparticles formulated with phospholipid and triglyceride, Pharm Res; 13:1406-10.

Hsu C. H., Cui Z., Mumper R. J. and Jay M.; (2003): Preparation and characterization of novel coenzyme Q10 nanoparticles engineered from microemulsion precursors, AAPS PharmSciTechnol; 4:1-12.

Hussain M. D. and Sexana V.; (2012): Poloxamer 407/TPGS mixed micelles for delivery of gambogic acid to breast and multidrug-resistant cancer, Int $\mathbf{J}$ nanomed; 7:713-21.

Jenning V., Thunemann A. F. and Gohla S. H.; (2000): Characterisation of a novel solid lipid nanoparticle carrier system based on binary mixtures of liquid and solid lipids, Int J Pharm; 199: 167-77.

Kabanov A., Batraoka E. and Alakhov V.; (2002): Pluronic block copolymers as novel polymer therapeutics for oral and gene delivery, J Control Rel; 82:189-212.

Leroux J. C., Allemann E., Doelker E. and Gurny R.; (1994): New approach for the preparation of nanoparticles by an emulsification-diffusion method, Eur $\mathbf{J}$ Pharm Biopharm; 41:14-8.

Liu J., Gong T., Wang C., Zhong Z. and Zhang Z.; (2007a): Solid lipid nanoparticles loaded with insulin by sodium cholate-phosphatidylcholine-based mixed micelles: preparation and characterization, Int J Pharm; 340: 153-62.

Lv Q., Yu A., Xi Y., Li H., Song Z., Cui J., Cao F. and Zhai G.; (2009): Development and evaluation of penciclovir-loaded solid lipid nanoparticles for topical delivery, Int J Pharm; 372:191-8.

Manjunath K., Reddy J. S. and Venkateswarlu V.; (2005): Solid lipid nanoparticles as drug delivery systems, Methods Find Exp Clin Pharmacol; 27:1-20.

Martins S., Sarmento B., Ferreira D. C. and Souto E. B.; (2007): Lipid-based colloidal carriers for peptide and protein delivery-liposomes versus lipid nanoparticles, Int J Nanomed; 2:595-607.

Mehnert W. and Mader K.; (2001): Solid lipid nanoparticles: Production, characterization and applications, Adv Drug Del Rev, 2001; 47:165-96.

Misra R., Acharya S., Dilnawaz F. and Sahoo S. K.; (2009): Sustained antibacterial activity of doxycycline-loaded poly(D,L-lactide-co-glycolide) and poly(epsiloncaprolactone) nanoparticles, Nanomedicine; 4(5): 519-30.

Mohanty C. and Sahoo S. K.; (2010): The in vitro stability and in vivo pharmacokinetics of curcumin prepared as an aqueous nanoparticulate formulation, Biomaterials 31, $6597-611$. 
Müller R. H., Mäder, K. and Gohla S.; (2000): Solid lipid nanoparticles (SLN) for controlled drug delivery - a review of the state of the art, Eur $\mathbf{J}$ Pharm Biopharm; 50: 161-77.

Mukherjee S., Ray S. and Thakur R. S.; (2007): The current status of solid lipid nanoparticles, Pharmabit; XV (1): 53-60.

Mulik R. S., Mahadik K. and Paradkar A.; (2009): Development of curcuminoids loaded poly(butyl) cyanoacrylate nanoparticles: Physicochemical characterization and stability study, Eur J Pharm Sci; 37:395-404.

Mulik R. S., Mönkkönen J., Juvonen R. O., Mahadik K. R., Paradkar A. R.; (2010): Transferrin mediated solid lipid nanoparticles containing curcumin: Enhanced in vitro anticancer activity by induction of apoptosis, Int J Pharm; 398:190-203.

Nayak A. P., Tiyaboonchai W., Patankar S., Madhusudhan B. and Souto E. B.; (2010): Curcuminoids-loaded lipid nanoparticles: Novel approach towards malaria treatment, Colloid Surf B: Biointerfaces; 81:263-73.

Nobili S., Lippi D., Witort E., Donnini M., Bausi L., Mini E. and Capaccioli S.; (2009): Natural compounds for cancer treatment and prevention, Pharmacol Res; 59:365-78.

Oh K. T., Bronich T. K. and Kabanov A. V.; (2004): Micellar formulations for drug delivery based on mixtures of hydrophobic and hydrophilic Pluronic block copolymers, J Control Rel,; 94(2-3):411-22.

Pan M. H., Lai C. S., Dushenkov S. and Ho C. T.; (2009): Modulation of inflammatory genes by natural dietary bioactive compounds, J Agric Food Chem; 57:4467-77.

Panyam J., Zhou W. Z., Prabha S., Sahoo S. K. and Labhasetwar V.; (2002): Rapid endolysosomal escape of poly(D,L-lactide-co-glycolide) nanoparticles: implications for drug and gene delivery, FASEB J; 16: 1217-26.

Sahu A., Kasoju N. and Bora U.; (2008): Fluorescence study of the curcumin-casein micelle complexation and its application as a drug nanocarrier to cancer cells, Bio-macromolecules; 9(10):2905-12.

Schäfer-Korting M., Mehnert W. and Korting H.; (2007): Lipid nanoparticles for improved topical application of drugs for skin diseases, Adv Drug Deliv Rev.; 59:427-43.

Schubert M. A. and Müller-Goymann C. C.; (2003): Solvent injection as a new approach for manufacturing lipid nanoparticles-evaluation of the method and process parameters, Eur J Pharm Biopharm; 55:125-31.

Shah M. and Pathak K.; (2010): Development and statistical optimization of solid lipid nanoparticles of simvastatin by using 23 Full-factorial design, AAPS PharmSciTech; 11(2):489-96.

Shaikh J., Ankola D. D., Beniwal V., Singh D. and Kumar M. N.; (2009): Nanoparticle encapsulation improves oral bioavailability of curcumin by at least 9-fold when compared to curcumin administered with piperine as absorption enhancer, Eur $\mathrm{J}$ Pharm Sci; 37(3-4):223-30.

Shoji Y. and Nakashima H.; (2004): Nutraceutics and delivery systems, J Drug Target; 12:385-91. 
Singh S., Bhardwaj P., Singh V., Aggarwal S. and Mandal U. K.; (2008): Synthesis of nanocrystalline calcium phosphate in microemulsion-effect of nature of surfactants, J Colloid Interface Sci.; 319:322-9.

Souto E. B. and Müller R. H.; (2006): Application of lipid nanoparticles (SLN and NLC) in food industry, J Food Tech; 4:90-5.

Souto E. B., Wissing S. A., Barbosa C. M. and Müller R. H.; (2004): Development of a controlled release formulation based on SLN and NLC for topical clotrimazole delivery, Int J Pharm; 278:71-7.

Tiyaboonchai W., Tungpradit W. and Plianbangchang P.; (2007): Formulation and characterization of curcuminoids loaded solid lipid nanoparticles, Int J Pharm; 337:299-306.

Tsai Y-M, Chien C-F, Lin L-C and Tsai T-H; (2011): Curcumin and its nano-formulation: The kinetics of tissue distribution and blood-brain barrier penetration, Int $\mathbf{J}$ Pharm; 416:331-8.

Wang W., Zhu R., Xie Q., Li A., Xiao Y., Li K., Liu H., Cui D., Chen Y. and Wang S.; (2012): Enhanced bioavailability and efficiency of curcumin for the treatment of asthma by its formulation in solid lipid nanoparticles, Int J Nanomed; 7: 366777.

Westesen K., Siekmann B. and Koch M. H. J.; (1993): Investigations on the physical state of lipid nanoparticles by synchrotron radiation X-ray diffraction, Int J Pharm; 93:189-99.

Wu W., Shen J., Banerjee P. and Zhou S.; (2011): Water-dispersible multifunctional hybrid nanogels for combined curcumin and photothermal therapy, Biomaterials, 2011; 32:598-609.

Yallapu M. M., Jaggi M. and Chauhan S. C.; (2012): Curcumin nanoformulations: a future nanomedicine for cancer, Drug Discovery Today; 17(1/2):71-80.

Zhang W., Shi Y., Chen Y., Ye J., Sha X. and Fang X.; (2011): Multifunctional Pluronic P123/F127 mixed polymeric micelles loaded with paclitaxel for the treatment of multidrug resistant tumors, Biomaterials; 32(11): 2894-906.

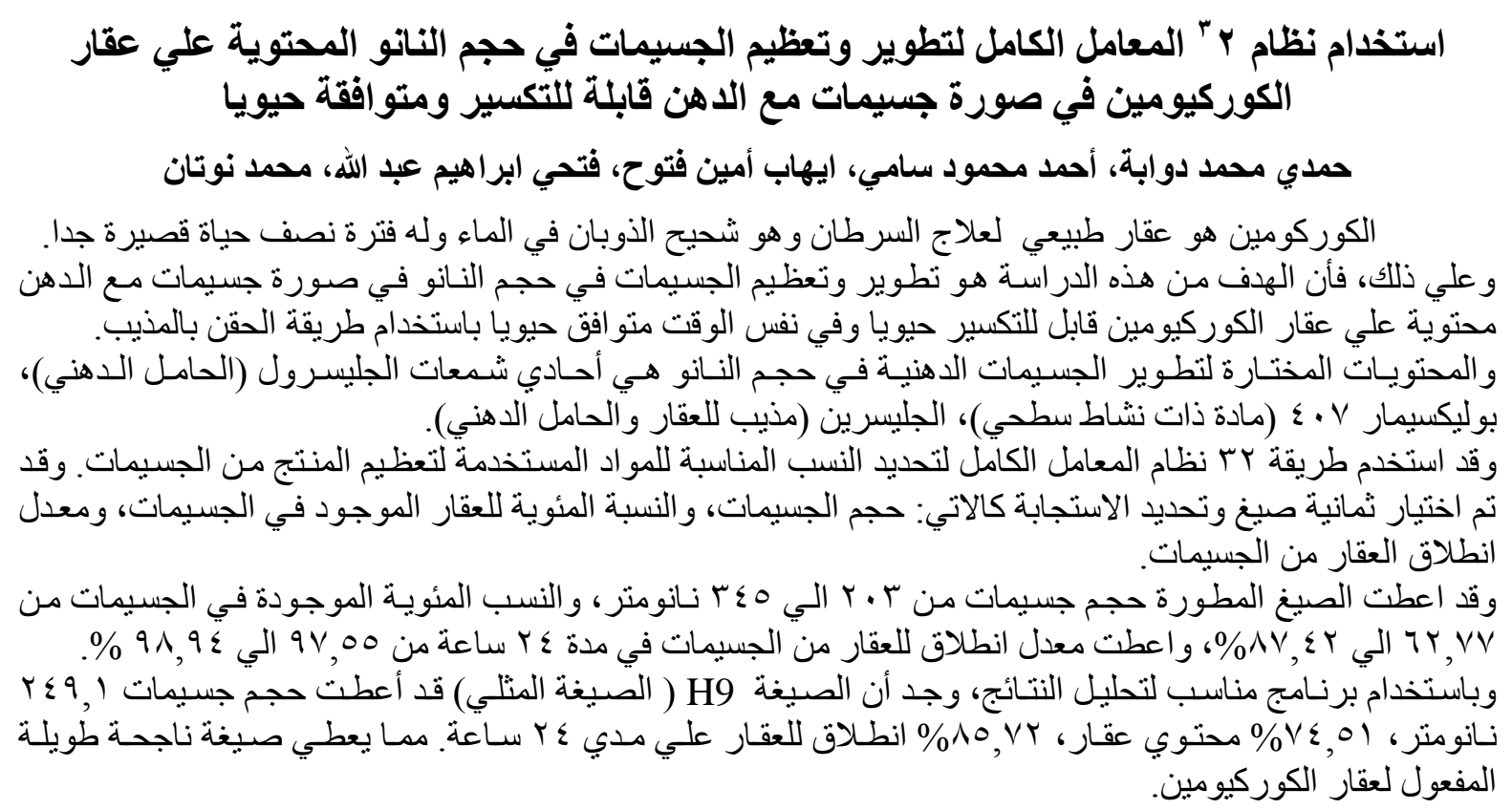


